Please do not remove this page

RMIT

UNIVERSITY

\title{
Low-temperature deposition of high-response piezoelectric thin films
}

Sriram, Sharath; Bhaskaran, Madhu; Mitchell, Arnan

https://researchrepository.rmit.edu.au/esploro/outputs/9921857933701341/filesAndLinks?institution=61RMIT_INST\&index=null

Sriram, S., Bhaskaran, M., \& Mitchell, A. (2010). Low-temperature deposition of high-response piezoelectric thin films. Scripta Materialia, 63(2), 189-191.

https://doi.org/10.1016/j.scriptamat.2010.03.041

Document Version: Accepted Manuscript

Published Version: https://doi.org/10.1016/j.scriptamat.2010.03.041

Repository homepage: https://researchrepository.rmit.edu.au

(c) 2010 Acta Materialia Inc. Published by Elsevier Ltd. All rights reserved.

Downloaded On 2023/04/26 22:55:26 +1000 
Thank you for downloading this document from the RMIT Research Repository.

The RMIT Research Repository is an open access database showcasing the research outputs of RMIT University researchers.

RMIT Research Repository: http://researchbank.rmit.edu.au/

\section{Citation:}

Sriram, S, Bhaskaran, M and Mitchell, A 2010, 'Low-temperature deposition of high-response piezoelectric thin films', Scripta Materialia, vol. 63, no. 2, pp. 189-191.

See this record in the RMIT Research Repository at: http://researchbank.rmit.edu.au/view/rmit:4015

Version: Accepted Manuscript

Copyright Statement: (c) 2010 Acta Materialia Inc. Published by Elsevier Ltd. All rights reserved.

Link to Published Version:

http://dx.doi.org/10.1016/j.scriptamat.2010.03.041 


\title{
Low temperature deposition of high response piezoelectric \\ thin films
}

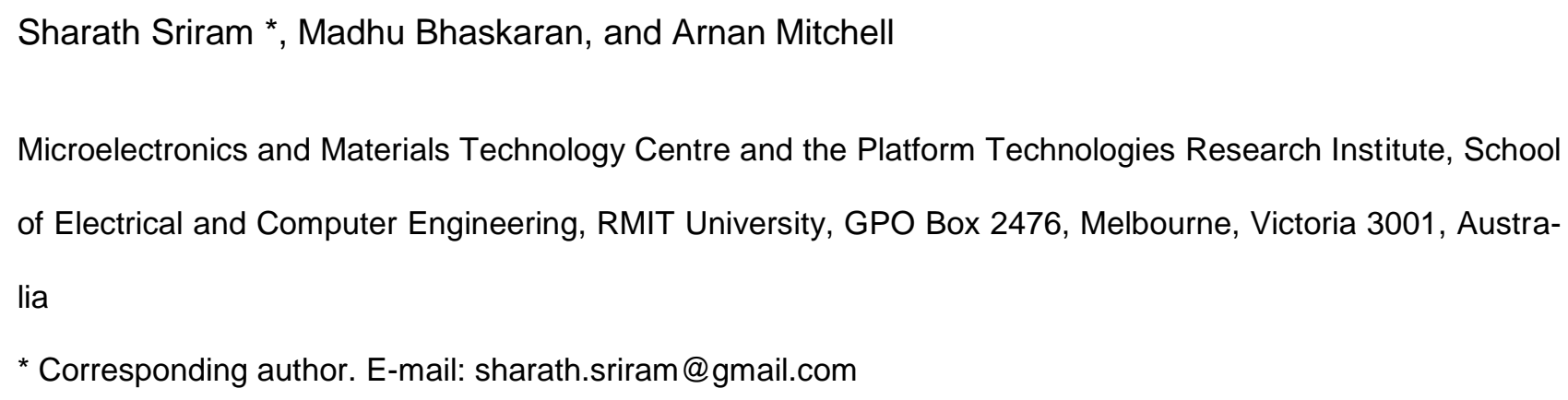

\begin{abstract}
Strontium-doping of the popular lead zirconate titanate results in improved piezoelectric response characteristics. We demonstrate the synthesis of these thin films at low temperature of $300{ }^{\circ} \mathrm{C}$ on silicon substrates. High response with an estimated piezoelectric coefficient $\left(d_{33}\right)$ value of 892 $\mathrm{pm} / \mathrm{V}$ was measured. Microstructural characterisation results showing strong $c$-axis texture and lattice guiding effects are also presented.
\end{abstract}

\section{KEYWORDS}

thin films; electro-mechanical properties; crystalline oxides; high-resolution electron microscopy; nanoindentation

\section{PACS INDEXING CODES}

77.65.Bn, 73.40.Rw, 81.70.Bt, 77.55.fg, 68.37.Lp, 68.35.Fx 
Lead zirconate titanate (PZT) thin films are reputed for their relatively high piezoelectric perform-

ance [1,2], based on value of the piezoelectric response coefficients such as the piezoelectric charge coefficient $d_{33}$. Reported values of $d_{33}$ for PZT thin films vary from $\sim 100-400 \mathrm{pm} / \mathrm{V}$. This relatively high response, often unmatched by other piezoelectric materials has led to the widespread use of PZT thin films in electronic devices for sensing and actuation, but often limited in processing capabilities by the high deposition temperature required $\left(600-700{ }^{\circ} \mathrm{C}\right)$.

The ability to successfully synthesise high performance piezoelectric thin films at lower temperatures provides the capability for more versatile integration with microelectronics, expanding the range of potential applications. Towards achieving this objective, the theoretical basis, synthesis, and characterisation of low temperature deposited, high piezoelectric response thin films are described in this article.

While PZT displays excellent piezoelectric response, it has been found that substituting strontium for a small percentage (about 1.6\%) of lead atoms at the ' $A$ '-site of the perovskite $\mathrm{ABO}_{3}$ structure of PZT enhances the piezoelectric response [3-7]. Thin films of PSZT (1.6 $\mu \mathrm{m}$ thick) were deposited on metal-coated silicon substrates by RF magnetron sputtering under the conditions given in Table 1. The silicon (100) substrates were first dipped in hydrofluoric acid to remove the native oxide layer. A diffusion barrier of $200 \mathrm{~nm}$ silicon dioxide was deposited, following which the gold electrode layer of $150 \mathrm{~nm}$ thickness was coated with the aid of a $15 \mathrm{~nm}$ titanium adhesion layer. All three layers were sequentially deposited by electron beam evaporation without breaking vacuum (at room temperature and under vacuum of $1 \times 10^{-7} \mathrm{Torr}$ ). Following this, sputtering was carried out, with the samples placed on a 3-inch resistive substrate heater, which was compatible with deposition in an oxygen atmosphere [8]. Very accurate control of temperature was achieved using an Eurotherm Controls, Inc. Model 808 temperature controller programmer. The post-deposition cooling rate was found to influence the degree of perovskite orientation in the thin films [9] based on which a cooling rate of $5 \stackrel{\circ}{\circ} \mathrm{C} / \mathrm{min}$ was chosen. The deposited thin films were extensively characterised using a combination of X-ray diffraction (under conditions as in Ref. [10]) and transmission electron microscopy (under conditions described in Refs. [11] and [12]). 
Piezoelectric response measurements on PSZT thin films samples were carried out using a nanoindenter (Fig. 1) to estimate the piezoelectric charge coefficient $d_{33}$, using the technique described in Ref. [7]. This technique was rigorously tested during development to ensure that the value obtained were quantitatively accurate, by ascertaining that similar values were obtained using both the nanoindenter and an atomic force microscope under the same testing arrangement $[7,13]$. Control samples comprising of amorphous silica thin films (no PSZT) were tested demonstrating no response under an applied electric field. Moreover, substrate bending did not influence the results obtained, as no force was applied on the films during testing - identical values were obtained for films deposited on silicon and alumina substrates. The samples were studied under the influence of the inverse piezoelectric effect, by applying an electric field and observing the variation in the film thickness. More than one top electrode was defined on samples of interest to study the uniformity of the piezoelectric response in different regions of the samples. The response variations (as peak-to-peak changes in film thickness) over an $8 \mu \mathrm{m} \times 8 \mu \mathrm{m}$ region under an applied electric peak-to-peak voltage of $32.8 \mathrm{~V}$ for a $1.6 \mu \mathrm{m}$ thick PSZT thin film sample is shown in Fig. 2. This figure shows bands of piezoelectric response variations which corresponded to a minimum peakto-peak thickness variation of $24.0 \mathrm{~nm}$ and a maximum of $29.3 \mathrm{~nm}$, which respectively correspond to $d_{33}$ values of $732 \mathrm{pm} / \mathrm{V}$ and $892 \mathrm{pm} / \mathrm{V}$. These piezoelectric response values were extracted from the raw data comprising of sinusoidal variations of the film thickness, averaging the measurements over five cycles.

This ultra-high value of $d_{33}$ (a maximum of $892 \mathrm{pm} / \mathrm{V}$ ), which is more than two times higher than the maximum value reported for PZT thin films on silicon (419 pm/V) [14], is an improvement of $50 \%$ (one and a half times) on the highest thin film $d_{33}$ value of $608 \mathrm{pm} / \mathrm{V}$ reported previously by us for PSZT thin films on gold [7]. The ultra-high piezoelectric response measured for these PSZT thin films can be attributed to three factors. Firstly, the PSZT thin films were deposited under optimised conditions following extensive analysis $[8,9,12]$. Secondly, the inclusion of the silicon dioxide layer improved the degree of preferential orientation in the PSZT thin films (Fig. 3), apparently caused by the increased guiding effect from the underlying gold layer (due to suppression of amorphous layer 
formation and enhanced gold texturing). Finally, and most importantly, the piezoelectric response

observed could be attributed to the modified (and expanded) unit cell of the PSZT thin films under study [10]. This larger unit cell creates more room for atomic displacements under an applied electric field [15], with the capability of causing higher levels of strain in the PSZT thin films.

The values of $d_{33}$ reported are termed 'effective values', as these apply for piezoelectric response measurements carried out on continuous thin films which are two-dimensional (length and width dimensions much greater than the film thickness). Lefki and Dormans [16] and Nagarajan et al. [17] have shown that the piezoelectric response of such films are damped by substrate clamping effects and in reality would have a component of error in the results. However, for thin film applications, the results presented in this article are very relevant.

The only comparable result demonstrating ultra-high piezoelectric response thin films with $d_{33}$ values up to $2000 \mathrm{pm} / \mathrm{V}$ was reported by Ouyang et al. [18]. While this result clearly demonstrates the ability to engineer films to attain high piezoelectric response, this deposition was carried out at 600 ${ }^{\circ} \mathrm{C}$ on $\mathrm{SrTiO}_{3}$ substrates. We demonstrate comparable high piezoelectric response for deposition at $300 \stackrel{\circ}{ } \mathrm{C}$ on metal-coated silicon substrates. This makes the process compatible with microsystems fabrication using widely accepted silicon technology.

In summary, this article presents results for the piezoelectric response characterisation of optimised low temperature piezoelectric thin films on silicon substrates. High response with a maximum $d_{33}$ value of $892 \mathrm{pm} / \mathrm{V}$ was measured, for the PSZT thin films deposited on metallised silicon substrates at $300^{\circ} \mathrm{C}$. The origin of the ultra-high response can be attributed to optimised deposition conditions, the pronounced preferential texture in the thin films, and a modified unit cell structure. 


\section{ACKNOWLEDGEMENTS}

The authors thank the Australian Research Council for project support (DP1092717), with MB acknowledging support in the form of an Australian Postdoctoral Fellowship. Partial support from the ARC Australian Research Network for Advanced Materials is also gratefully acknowledged.

\section{REFERENCES}

[1] B. Jaffe, W.R. Cook, H. Jaffe, Piezoelectric Ceramics, Academic, New York, USA, 1971.

[2] Y. Nemirovsky, A. Nemirovsky, P. Muralt, N. Setter, Sens. Actuators A 56 (1996) 239.

[3] C. Bedoya, Ch. Muller, J.-L. Baudour, V. Madigou, M. Anne, M. Roubin, Mater. Sci. Eng. B $75(2000) 43$.

[4] Y. Yu, R.N. Singh, J. Appl. Phys. 88 (2000) 7249.

[5] Y. Yu, J. Tu, R.N. Singh, J. Am. Ceram. Soc. 84 (2001) 333.

[6] H. Zheng, I.M. Reaney, W.E. Lee, N. Jones, H. Thomas, J. Am. Ceram. Soc. 85 (2002) 207.

[7] S. Sriram, M. Bhaskaran, A.S. Holland, K.T. Short, B.A. Latella, J. Appl. Phys. 101 (2007) 104910.

[8] S. Sriram, M. Bhaskaran, J. du Plessis, K.T. Short, V.P. Sivan, A.S. Holland, Micron 40 (2009) 104

[9] S. Sriram, M. Bhaskaran, A.S. Holland, Semicond. Sci. Technol. 21 (2006) 1236.

[10] M. Bhaskaran, S. Sriram, D.R.G. Mitchell, K.T. Short, A.S. Holland, Thin Solid Films 516 (2008) 8101.

[11] S. Sriram, M. Bhaskaran, D.R.G. Mitchell, A.S. Holland, A. Mitchell, Microsc. Microanal. 15 (2009) 30.

[12] S. Sriram, M. Bhaskaran, D.R.G. Mitchell, A. Mitchell, Cryst. Growth Des. 10 (2010) 761.

[13] S. Sriram, M. Bhaskaran, K.T. Short, G.I. Matthews, A.S. Holland, Micron 40 (2009) 109.

[14] V. Snitka, A. Ulcinas, K. Nemiciauskas, V. Lendraitis, Microelectron. Eng. 83 (2006) 1456.

[15] X. Ren, Nature Mater. 3 (2004) 91.

[16] K. Lefki, G.J.M. Dormans, J. Appl. Phys. 76 (1994) 1764. 
[17] V. Nagarajan, A. Roytburd, A. Stanishevsky, S. Prasertchoung, T. Zhao, L. Chen, J. Melngailis, O. Auciello, R. Ramesh, Nature Mater. 2 (2003) 43.

[18] J. Ouyang, J. Slusker, I. Levin, D.-M. Kim, C.-B. Eom, R. Ramesh, A. L. Roytburd, Adv. Funct. Mater. 17 (2007) 2094. 


\section{TABLE (WITH CAPTION)}

Table 1. RF magnetron sputtering conditions for PSZT.

\begin{tabular}{lc} 
Target & $\left(\mathrm{Pb}_{0.92} \mathrm{Sr}_{0.08}\right)\left(\mathrm{Zr}_{0.65} \mathrm{Ti}_{0.35}\right) \mathrm{O}_{3}$ \\
Target diameter & $100 \mathrm{~mm}$ \\
RF power & $100 \mathrm{~W}$ \\
Target to substrate distance & $70 \mathrm{~mm}$ \\
Process gas & $10 \%$ oxygen in argon \\
Base pressure & $9.0 \times 10^{-6} \mathrm{Torr}$ \\
Sputtering pressure & $1.0 \times 10^{-2} \mathrm{Torr}$ \\
Substrate temperature & $300 \stackrel{\circ}{\circ}$ \\
Temperature ramp-up rate & $10{ }^{\circ} \mathrm{C} / \mathrm{min}$ \\
Temperature ramp-down rate & $5 \stackrel{\circ}{\circ} / \mathrm{min}$ \\
Sputtering duration & $4 \mathrm{~h}$ \\
\hline
\end{tabular}




\section{FIGURE CAPTIONS}

FIG. 1. Schematic representation of the nanoindentation-based piezoelectric response measurement arrangement.

FIG. 2. Result from mapping the piezoelectric response over an $8 \mu \mathrm{m} \times 8 \mu \mathrm{m}$ area on the PSZT thin film surface.

FIG. 3. Characterisation results for the PSZT thin film samples: (a) X-ray diffractogram showing the strong preferential orientation of PSZT (104) and Au (111); (b) High resolution transmission electron micrograph showing the guiding effect of Au (111) on PSZT (104). 


\section{Nanoindenter tip}

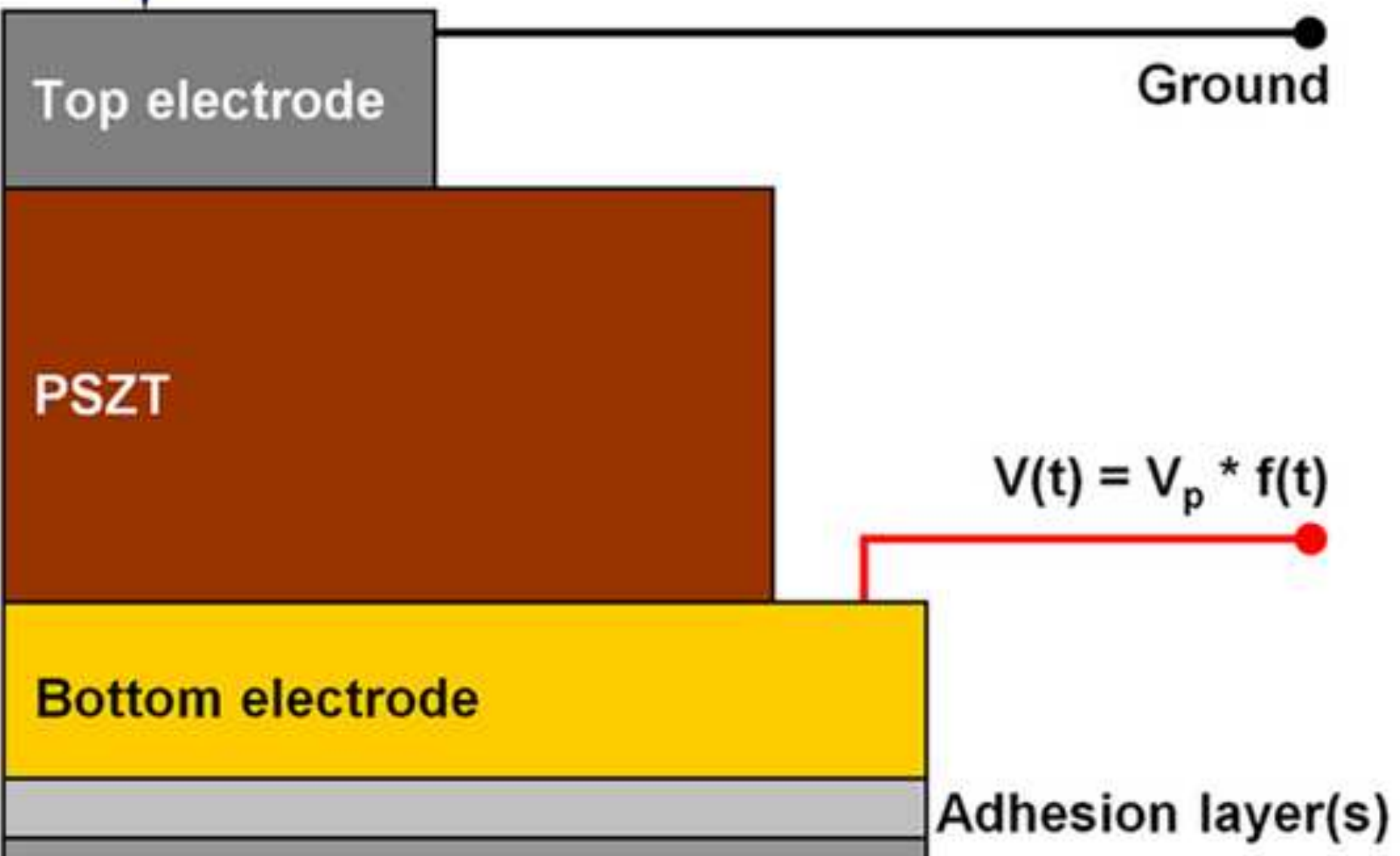

(100) Silicon substrate 
Click here to download high resolution image

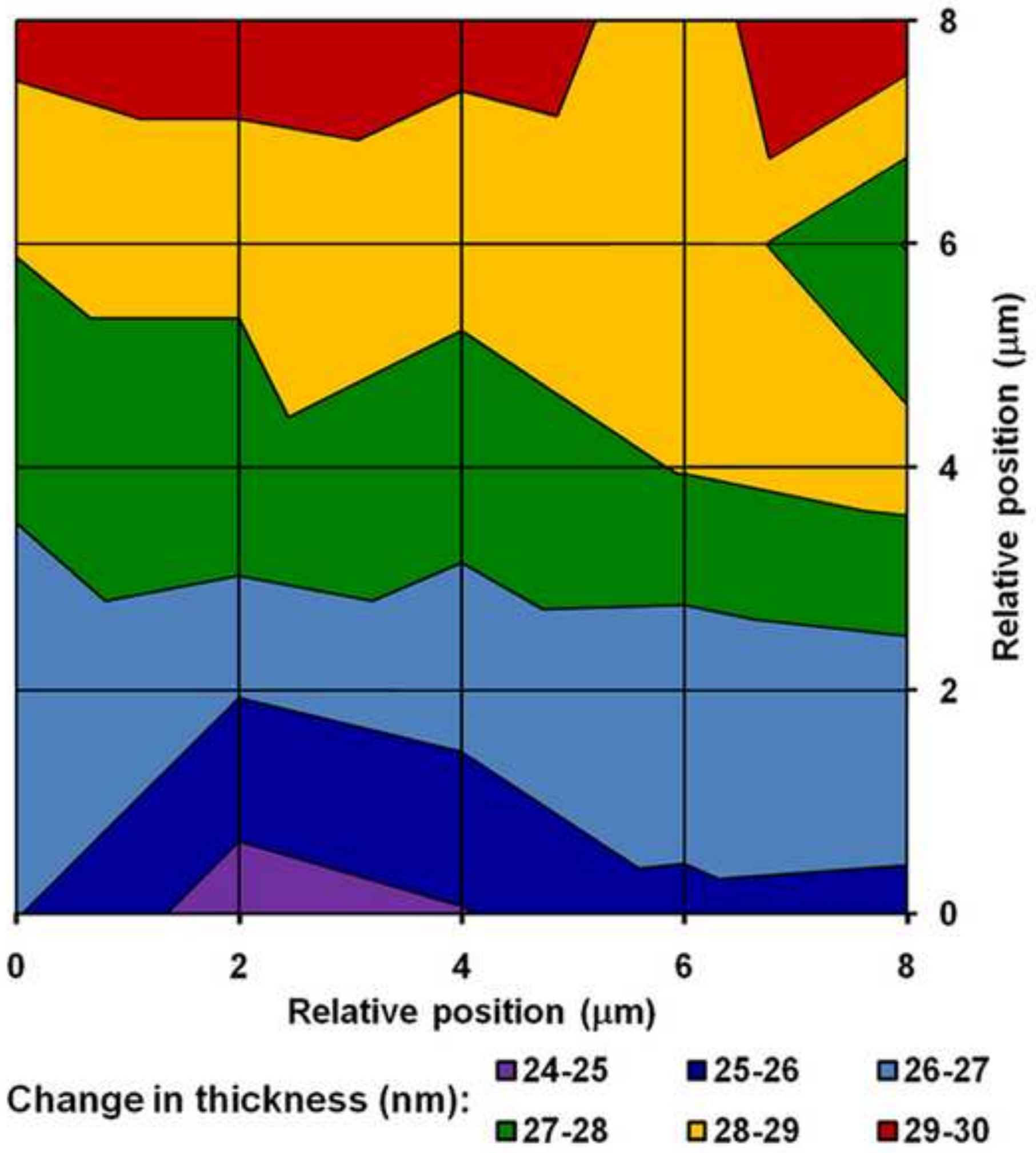




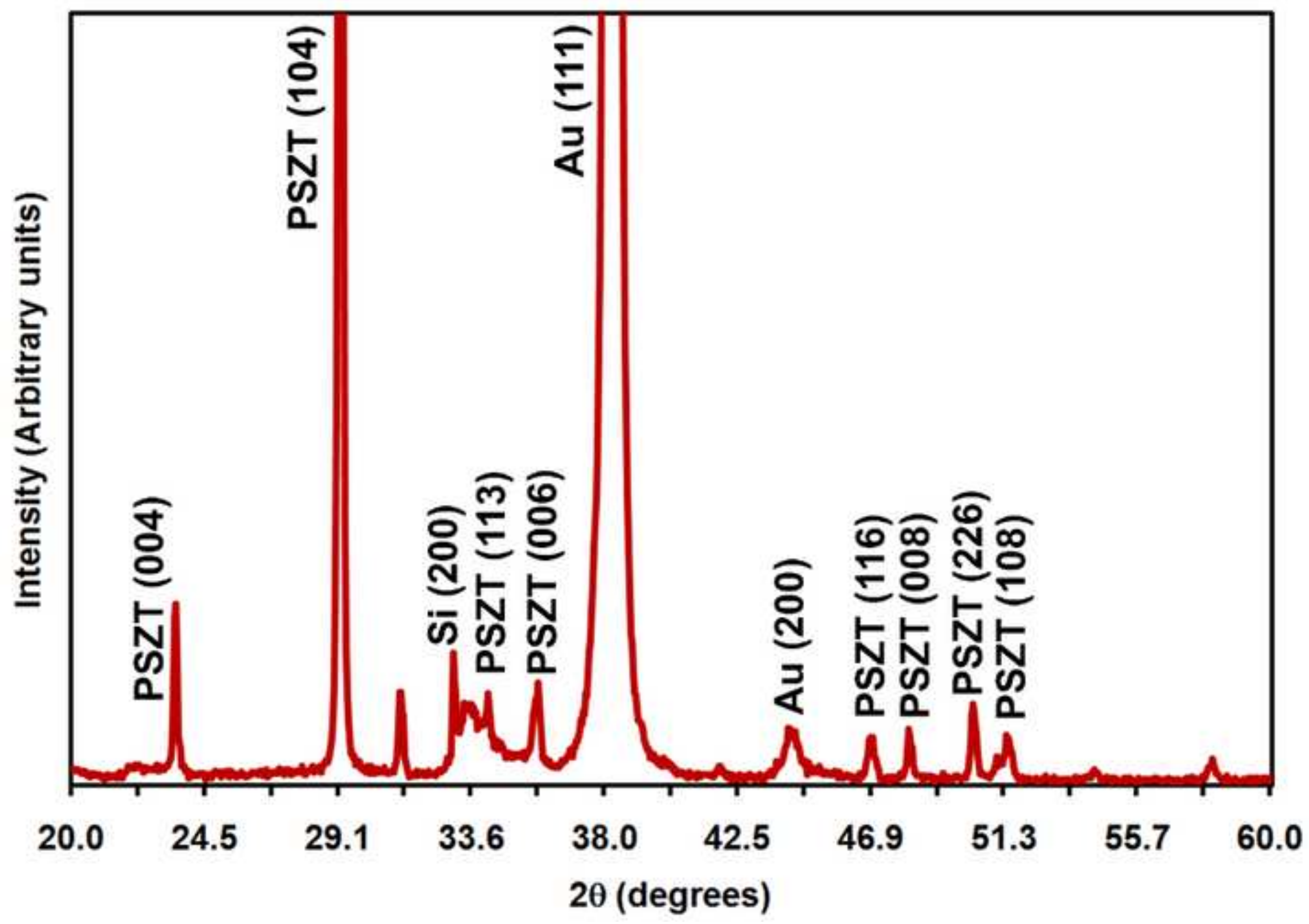


Click here to download high resolution image

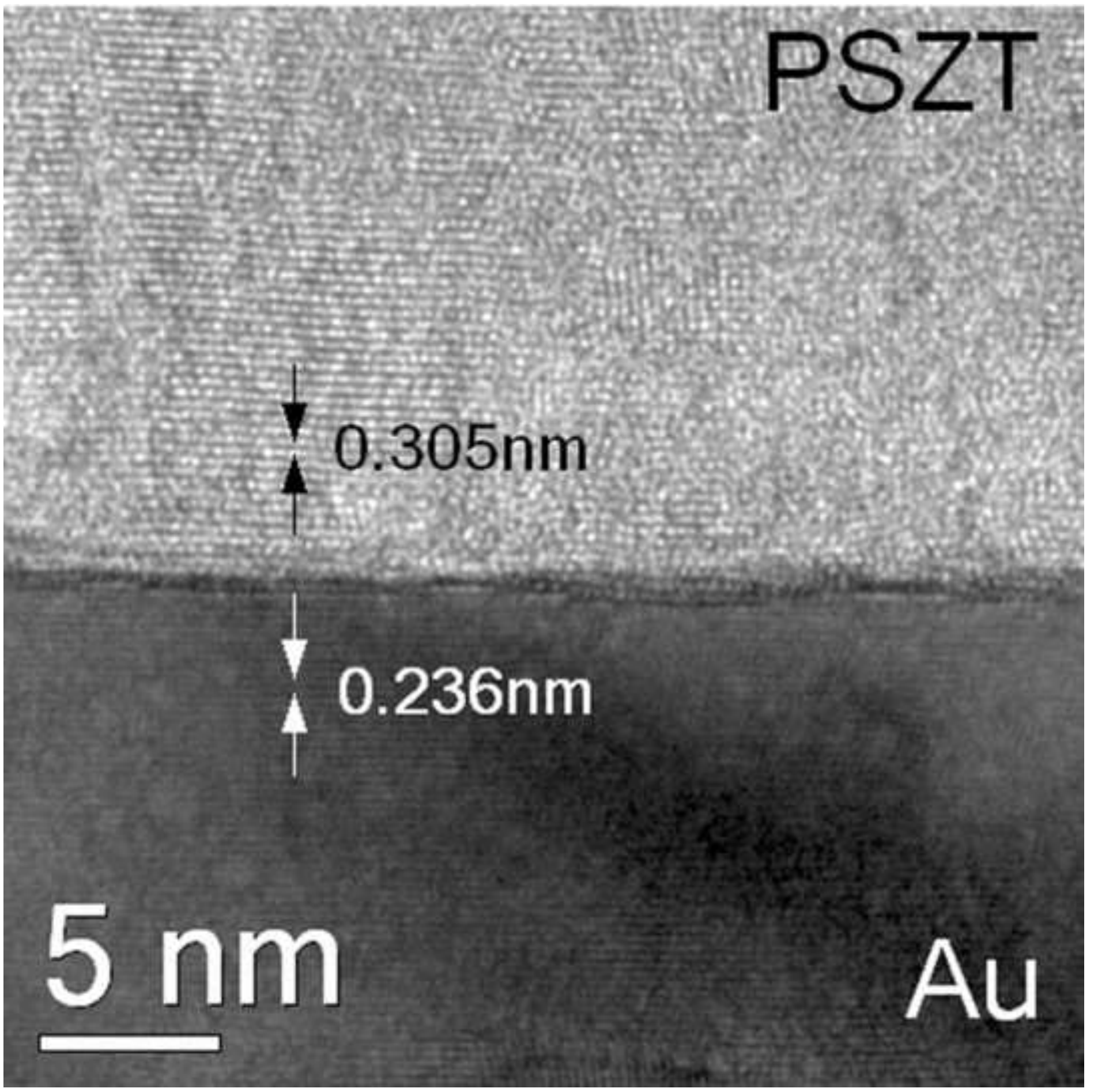

